\title{
GroEL (Hsp60) of Clostridium difficile is involved in cell adherence
}

Université de Paris-Sud, Faculté de Pharmacie, Département de

Microbiologie, 5 rue JB Clément, F-92296

Châtenay-Malabry cedex, France

\author{
Claire Hennequin, Fabrice Porcheray, Anne-Judith Waligora-Dupriet, \\ Anne Collignon, Marie-Claude Barc, Pierre Bourlioux \\ and Tuomo Karjalainen
}

Author for correspondence: Tuomo Karjalainen. Tel: +331468355 49. Fax: +33146831303. e-mail: tuomo.karjalainen@cep.u-psud.fr

\begin{abstract}
Previous results have demonstrated that adherence of Clostridium difficile to tissue culture cells is augmented by various stresses; this study focussed on whether the GroEL heat shock protein is implicated in this process. The 1940 bp groESL operon of C. difficile was isolated by PCR. The 1623 bp groEL gene is highly conserved between various $C$. difficile isolates as determined by RFLPPCR and DNA sequencing, and the operon is present in one copy on the bacterial chromosome. The $58 \mathrm{kDa}$ GroEL protein was expressed in Escherichia coli in fusion with glutathione $S$-transferase and the fusion protein was purified from IPTG-induced bacterial lysates by affinity chromatography on glutathione-Sepharose. A polyclonal, monospecific antiserum was obtained for GroEL which established by immunoelectron microscopy, indirect immunofluorescence and immunoblot analysis that GroEL is released extracellularly after heat shock and can be surface associated. Cell fractionation experiments suggest that GroEL is predominantly cytoplasmic and membrane bound. GroEL-specific antibodies as well as the purified protein partially inhibited $C$. difficile cell attachment and expression of the protein was induced by cell contact, suggesting a role for GroEL in cell adherence.
\end{abstract}

Keywords: Clostridium difficile, adherence, pathogenesis, GroEL, heat shock

\section{INTRODUCTION}

Clostridium difficile is recognized as the major aetiological agent of nosocomial infections such as pseudomembranous colitis, and antibiotic-associated colitis and diarrhoea (Bartlett et al., 1978; George, 1984). Several potential and putative virulence factors that could play a role in C. difficile pathogenesis have been identified. Virulence is mainly due to the production of two protein exotoxins: toxins A and B, although other toxic factors have been described (Lyerly et al., 1988). There is considerable evidence that some strains are more virulent than others; a number of factors have been proposed to explain inter-strain diversity: (i) the capsule, an antiphagocytic factor (Davies \& Borriello, 1990); (ii) proteolytic enzymes, which may play a role in

Abbreviations: GST, glutathione S-transferase; HSP, heat shock protein The nucleotide sequence of the groESL locus of strain 79-685 was assigned GenBank accession number AF093568; that of strain ATCC 53603 was assigned GenBank accession number AF159449. The nucleotide sequence of the 16S rDNA of strain 79-685 was assigned GenBank number AF072474. releasing suitable substrates from available protein sources for metabolism and which could be involved in mucus penetration (Poilane et al., 1998; Seddon \& Borriello, 1992); (iii) adhesins, which are involved in mucus and cell association (Borriello et al., 1988a; Eveillard et al., 1993; Karjalainen et al., 1994); (iv) fimbriae, the role of which is obscure (Borriello et al., 1988a); and (v) flagella, for which no role in C. difficile colonization has yet been assigned (Tasteyre et al., 2000).

One aspect of $C$. difficile pathogenesis that has been studied by us is its interaction with target cells and identification of the bacterial factors involved in this process (Eveillard et al., 1993; Karjalainen et al., 1994). Adhesion and colonization of animal tissue by bacteria is an important step in establishing infection. It is probable that without attachment, C. difficile cannot colonize and will be quickly removed by non-specific host defence mechanisms. It is likely that after destruction of normal flora by antibiotic treatment, $C$. difficile finds itself in a stressful environment that could serve as a stimulus for cell attachment and subsequent 
colonization. We have previously observed that $C$. difficile cell adherence is enhanced by heat, osmotic and acid shock as well as iron insufficiency (Waligora et al., 1999). Furthermore, attachment was partially inhibited by an antiserum raised to GroEL of Mycobacterium leprae. This evoked a potential role for heat shock proteins (HSPs) in adherence. Therefore, we were interested in finding out whether GroEL, a member of the Hsp60 family of chaperonins, plays a role in $C$. difficile colonization.

In this study we undertook the isolation of the C. difficile groELS operon from two strains, and characterization and expression of the $h s p 60$ gene. PCR amplification of the groEL gene coupled with RFLP analysis was used in an attempt to differentiate between clinical isolates. The role of Hsp60 in cell adhesion was examined by inhibition assays using antiserum and the purified Hsp60 protein, and by investigating the localization of the protein in various cell compartments.

\section{METHODS}

C. difficile strains and growth conditions. C. difficile isolates investigated are presented in Table 1 . The strains were grown under anaerobic conditions in Tryptone Glucose Yeast (TGY) infusion broth (Difco).

Isolation of C. difficile groEL by PCR, and nucleotide sequencing. Genomic DNA of C. difficile strains 79-685 and ATCC 53603 was isolated using the Puregene kit (Gentra) and resuspended in TE buffer $(10 \mathrm{mM}$ Tris $/ \mathrm{HCl}, 1 \mathrm{mM}$ EDTA, $\mathrm{pH} 8$ ) at $1 \mu \mathrm{g} \mathrm{m}{ }^{-1}$. Initial amplification of a $600 \mathrm{bp}$ fragment of the groELS operon of strains 79-685 and ATCC 53603 was carried out using primers based on the Clostridium perfringens groEL gene (GenBank accession no. X62914) (Rusanganwa

Table 1. Clostridium difficile strains used in this study

ND, Not determined.

\begin{tabular}{|c|c|c|c|}
\hline Strain & Toxigenicity & Serogroup & Origin \\
\hline $79-685$ & + & S3 & $\begin{array}{l}\text { Institut de } \\
\text { Bactériologie* }\end{array}$ \\
\hline VPI 10463 & + & G & Dr T. D. Wilkins† \\
\hline ATCC 43594 & + & A & Dr M Delméeł \\
\hline ATCC 43593 & - & B & Dr M Delméeł \\
\hline ATCC 53596 & + & $\mathrm{C}$ & Dr M Delméeł \\
\hline ATCC 53598 & - & $\mathrm{D}$ & Dr M Delméeł \\
\hline ATCC 53598 & $\mathrm{~A}-\mathrm{B}+$ & $\mathrm{F}$ & Dr M Delméeł \\
\hline ATCC 53599 & + & G & Dr M Delméeł \\
\hline ATCC 53600 & + & $\mathrm{H}$ & Dr M Delméeł \\
\hline ATCC 53601 & - & I & Dr M Delméeł \\
\hline ATCC 53602 & - & K & Dr M Delméef \\
\hline ATCC 53603 & - & $\mathrm{X}$ & Dr M Delméeł \\
\hline 630 & + & ND & Dr P. Mullany \\
\hline
\end{tabular}

*Strasbourg, France.

† Virginia Polytechnic Institute, Blacksburg, VA, USA.

‡Université Catholique de Louvain (UCL), Brussels, Belgium.

SEastman Dental Institute, London, UK. et al., 1992). PCR was carried out in a $100 \mu$ l reaction volume containing $5 \mu \mathrm{l}$ each primer at $20 \mathrm{pmol}^{\mu \mathrm{l}^{-1}}$ (primers 5'-GGNGAYGGNACNACNACNGCNACNGT-3' and $5^{\prime}$ TCNCCRAANCCNGGNGCYTTNACNGC-3' where $\mathrm{N}=$ $\mathrm{A} / \mathrm{G} / \mathrm{C} / \mathrm{T} ; \mathrm{Y}=\mathrm{C} / \mathrm{T} ; \mathrm{R}=\mathrm{A} / \mathrm{G}, \mathrm{W}=\mathrm{A} / \mathrm{T}), 8 \mu \mathrm{l} 25 \mathrm{mM}$ $\mathrm{MgCl}_{2}, 8 \mu \mathrm{l}$ of a mix of dATP, dTTP, dGTP and dCTP (2.5 mM each), $10 \mu \mathrm{l} 10 \times$ reaction buffer (Promega) and $0.2 \mu \mathrm{l}$

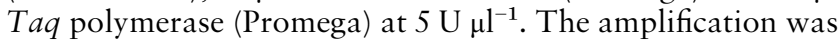
performed in a Perkin Elmer Cetus Thermal Cycler $480: 95^{\circ} \mathrm{C}$ 5 min followed by 34 cycles of denaturation $\left(95^{\circ} \mathrm{C} 1 \mathrm{~min}\right)$, annealing of primers $\left(55^{\circ} \mathrm{C} 1 \mathrm{~min}\right)$ and polymerization of DNA $\left(72{ }^{\circ} \mathrm{C}, 2 \mathrm{~min}\right)$. The last cycle was carried out at $72{ }^{\circ} \mathrm{C}$ for $10 \mathrm{~min}$. The presence of an amplified product was confirmed by electrophoresis in a $1 \%$ agarose gel.

The entire operon from the translation-initiation codon of GroES until the stop codon of GroEL was subsequently obtained by PCR using primers designed on basis of alignment of the $5^{\prime}$ ends of the groES gene of Clostridium thermocellum (P48212 and P48223), C. perfringens (P26821) and Clostridium acetinobutylicum (M74572), and the $3^{\prime}$ ends of the groEL gene of the same bacteria (primers 5'-ATGARWATYARACCAYTWGGWGACAFRG-3' and 5'-TTARTACATTCCGYCCATKCCCCRTWCC-3'). Finally, sequences upstream of the operon were obtained by amplification with groEL-specific internal primer (5'-CAATAACAGCTAATACATCAC-3') and a promoter-specific primer (5'-TGCTTCTGCAGGTACAGCTAAT $-3^{\prime}$ ), and sequences downstream were obtained with the primer pair 5'-GGAATAGTAGCTGGTGGAGG-3' and 5'-TACTGATTATCTAAATATGTG-3'. These primers were designed on the basis of the genome sequence of $C$. difficile strain 630 that recently became available on the Internet (http://www.sanger.ac.uk).

Amplified products were purified by the Wizard Gel Extraction Kit (Promega) and the nucleotide sequences of both strands of the amplified products were obtained by using the Taq DyeDeoxy and Big Dye Terminator Cycle sequencing kits purchased from Perkin Elmer. The labelled extension products were analysed with an ABI PRISM 310 Genetic Analyser (Perkin Elmer). Additional primers were designed to obtain additional internal sequence.

Southern blotting. DNA of C. difficile strains was prepared as described above. DNA (2 $\mu \mathrm{g})$ was digested with HindIII and AccI according to instructions provided by the supplier (Pharmacia), the fragments separated through a $0.8 \%$ agarose gel and electrically transferred to a nylon membrane (Roche). A $340 \mathrm{bp}$ amplified PCR product of the groEL gene of C. difficile strain 79-685 was used as a probe, labelled in a standard PCR reaction (see above) with $25 \mu$ of the following nucleotide mix: $25 \mu \mathrm{l} 1 \mathrm{mM}$ digoxigenin-11-dUTP (Roche), $4 \cdot 6 \mu \mathrm{l} 10 \mathrm{mM}$ dTTP, $7 \cdot 1 \mu \mathrm{l} 10 \mathrm{mM}$ dATP, $7 \cdot 1 \mu \mathrm{l} 10 \mathrm{mM}$ dGTP, $7 \cdot 1 \mu \mathrm{l} 10 \mathrm{mM}$ dCTP (Promega) and $2 \cdot 5 \mu \mathrm{l}$ sterile water. Hybridization was carried out overnight at $42{ }^{\circ} \mathrm{C}$ with $1 \mu \mathrm{g}$ probe (ml DIG Easy Hyb) ${ }^{-1}$ (Roche). The subsequent washing steps and detection with CSPD (disodium 3-\{4-methoxyspiro[1,2-dioxetane-3,2'-(5'-chloro) tricyclo $\left(3.3 .1 .1^{3,7}\right)$ decan]4-yl\} phenyl phosphate; Roche) were carried out as recommended by the manufacturer.

RFLP analysis. A 1448 bp amplicon encompassing groEL was obtained by PCR as described above on genomic DNA from 12 strains using primers 5'-ATGARWATYARACCAYTWGGWGACAFRG-3' and 5'-TACAACAGCTACTCCTCCAGC-3'. The DNA was digested with eight restriction enzymes under the conditions recommended by the supplier (New England Biolabs). These digests were then subjected to electrophoresis in a $1 \%$ agarose gel. 
Cloning of C. difficile 79-685 groEL into an expression vector. Two oligonucleotide primers, PGEX1 (5'-ATTGAATTCGAGGGGTTTAAAATGGCTA-3') and PGEX2 (5'-TTAGTACATTCCGTCCATGCCCGTTCCT-3'), incorporating an EcoRI site in PGEX1 (shown in bold; the translationinitiation codon of GroEL is underlined), were synthesized and used to amplify by PCR the full-length coding region of groEL of strain 79-685 in a standard amplification reaction as described above. The resulting $1.6 \mathrm{~kb}$ DNA product was blunt-ended by Klenow [1 $\mathrm{U}$ in $30 \mu$ l One-Phor-All buffer (Pharmacia) for $2 \mathrm{~h}$ at $37^{\circ} \mathrm{C}$ ] and subsequently digested with EcoRI. The fragment was ligated (1 U T4 ligase; Life Technologies) into the EcoRI and SmaI sites of pGEX-6P-1 (Pharmacia) and transformed into E. coli XLOLR (Stratagene). A transformant was identified carrying a plasmid which, after nucleotide sequencing of the junction between vector and insert, was found to be capable of producing an inframe fusion protein between glutathione $S$-transferase (GST) and GroEL. This plasmid was transformed into E. coli BL21.

Expression and purification of the fusion protein. An overnight culture of E. coli BL21 containing pGEX-6P1-groEL grown in LB broth (Difco) containing carbenicillin $\left(50 \mu \mathrm{g} \mathrm{ml}^{-1}\right)$ was diluted $1: 100$ into $4 \mathrm{l} \mathrm{LB}$ medium containing carbenicillin and the culture grown to $\mathrm{OD}_{600} 0.6$ at $37^{\circ} \mathrm{C}$. The expression of the fusion protein was induced by addition of $1 \mathrm{mM}$ IPTG and the culture was continued for $12 \mathrm{~h}$ at room temperature. Bacteria were collected by centrifugation and resuspended in $200 \mathrm{ml} 20 \mathrm{mM}$ Tris/ $\mathrm{HCl}, \mathrm{pH} 7 \cdot 5$. The bacteria were lysed by incubation with freshly prepared lysozyme at $100 \mu \mathrm{g} \mathrm{m}^{-1}$ (Sigma) for $15 \mathrm{~min}$ at $30^{\circ} \mathrm{C}$, followed by sonication at intervals of $5 \mathrm{~s}$ for $1 \mathrm{~h}$ at $80 \%$ power (Bioblock Scientific 72442 Vibra Cell) and three successive freeze-thaw cycles. Insoluble material was removed by centrifugation at $14000 \mathrm{~g}$ for $10 \mathrm{~min}$, and the fusion protein was purified from the supernatant by a single-step affinity chromatography using glutathione-Sepharose-4B and protocols from Pharmacia. A $2 \mathrm{ml}$ bed volume was used for each $200 \mathrm{ml}$ sonicate; the column was washed three times with $20 \mathrm{ml}$ PBS, followed by cleavage of the GroEL moiety bound to glutathione-Sepharose with $80 \mathrm{U}$ Prescission protease (Amersham Pharmacia Biotech) per $1 \mathrm{ml}$ bed volume.

Antibodies. A rabbit polyclonal, monospecific GroEL antiserum was prepared. The band corresponding to the purified C. difficile GroEL protein was cut out of the PAGE gel and was lyophilized. Purified protein $(200 \mu \mathrm{g})$ was injected with Freund's complete adjuvant into New Zealand White rabbits (AGROBIO), followed by four boosters with $100 \mu \mathrm{g}$ protein in Freund's incomplete adjuvant at day 14, 28 and 42. The rabbits were killed and bled $21 \mathrm{~d}$ after the last injection. Antibodies were purified on protein A-Sepharose (PharmaciaBiotech) according to the supplier's recommendations and used at a 1:2000 dilution in immunoblots.

Antiserum against $C$. difficile was produced as described previously (Karjalainen et al., 1994). Monoclonal antibodies raised against the $65 \mathrm{kDa}$ HSP of $M$. leprae were obtained from UNPD/World Bank/WHO Special Program for Research and Training in Tropical Diseases, Atlanta, GA.

$\mathrm{N}$-terminal protein sequence. The purified C. difficile GroEL protein was electroblotted onto a PVDF membrane (Roche) with $50 \mathrm{mM}$ Tris/ $\mathrm{HCl}, 50 \mathrm{mM}$ boric acid buffer and stained with $0 \cdot 1 \%$ amido black (Sigma). The band was excised and Nterminal sequencing was performed by the Laboratory of Microsequencing of Proteins, Pasteur Institute, Paris.

Immunoelectron microscopy. After adsorption of a bacterial preparation to Formvar-coated grids (Sigma) for $5 \mathrm{~min}$, the grids were floated on PBS with 1\% BSA for $30 \mathrm{~min}$, then incubated with GroEL antibodies diluted 1:10 for $1 \mathrm{~h}$ and washed three times in PBS. They were incubated with a $1: 20$ dilution of protein A conjugated with $10 \mathrm{~nm}$ diameter colloidal gold particles (Sigma) for $1 \mathrm{~h}$, washed three times with PBS and fixed with $3 \%$ glutaraldehyde. After three washings the grids were stained with phosphotungstic acid before observation by transmission electron microscopy.

Immunofluorescence. Bacteria were cultured for 24 h at $37^{\circ} \mathrm{C}$ in TGY and shocked at $43^{\circ} \mathrm{C}$ for $20 \mathrm{~min}$. A drop of the PBSwashed culture was deposited on a microscope slide and dried. The slide was immersed in PBS ( $\mathrm{pH} 7 \cdot 2$ ) $/ 5 \%$ skimmed milk ( $1 \mathrm{~h}$, room temp.), followed by a $1 \mathrm{~h}$ incubation with protein A purified anti-GroEL antibodies (dilution 1:2000 in the same solution). The slide was washed with PBS $(\mathrm{pH} 7 \cdot 2) / 0 \cdot 1 \%$ skimmed milk and incubated for $15 \mathrm{~min}$ with tetramethylrhodamine isothiocyanate (TRITC)-conjugated antimouse IgG antibody (Immunotech; 1:20 dilution in PBS/5\% skimmed milk). After washing, the specimens were examined with a $100 \times$ oil-immersion objective using a Leitz Aristoplan microscope with epifluorescence coupled to an Image Analyzer Visiolab 1000 (Biocom).

Fractionation. Bacterial proteins were separated into four compartments: supernatant, cell wall, membrane and cytoplasm, using a protocol described for Listeria monocytogenes (Jonquières et al., 1999). Equivalent amounts of each fraction, corresponding to $20 \mathrm{ml}$ bacterial culture, were separated by SDS-PAGE (Laemmli, 1970) using a $7 \cdot 5 \%$ SDS-polyacrylamide gel, transferred to nitrocellulose and submitted to immunodetection as described below. The purity of the fractions was verified by studying two proteins with known cellular locations. Cwp66-C was used as a marker for the cell wall fraction (a peptidoglycan-attached protein, our unpublished data); PepC, a cytoplasmic peptidase reported to be adsorbed to the inner face of the cytoplasmic membrane in Lactococcus lactis (Jonquières et al., 1999), was used as a marker for the cytoplasmic and membrane fractions.

The presence of GroEL in the supernatant of exponentialphase bacteria was investigated by precipitating proteins by $70 \%$ trichloroacetic acid as described by Schubert et al. (2000) and by detecting the presence of GroEL by immunoblotting as described below.

Immunoblotting. Proteins separated by SDS-PAGE were transferred electrically onto nitrocellulose membrane for immunoblotting. The nitrocellulose membrane was incubated for $1 \mathrm{~h}$ at room temperature in blocking buffer $(5 \%$ skimmed milk in TNT [10 mM Tris/ $\mathrm{HCl}, \mathrm{pH} 8.0,150 \mathrm{mM} \mathrm{NaCl}$, $0.05 \%$ Tween ]) and then $1 \mathrm{~h}$ in the appropriate dilution of the specific antibody. The membranes were washed in TNT and bound antibodies were detected with goat anti-rabbit IgGalkaline phosphatase conjugate (1:2500 dilution; Sigma) with nitro blue tetrazolium and 5-bromo-4-chloro-3-indolyl phosphate (Life Technologies) as substrates.

Cell-adherence and adherence-inhibition assays. Cell-adherence assays were performed as previously described using the Vero cell line (Karjalainen et al., 1994). For adherence inhibition with antibodies, bacteria that had been washed twice in PBS and heat shocked at $48^{\circ} \mathrm{C}$ or $60^{\circ} \mathrm{C}$ for $20 \mathrm{~min}$ were preincubated with antibodies $(1: 10,1: 100$ or $1: 1000$ dilution in TNT $+5 \%$ skimmed milk) for $30 \mathrm{~min}$ before contact with cells $\left(1 \mathrm{~h}\right.$ at $37^{\circ} \mathrm{C}$ under anaerobic conditions). When inhibitions were carried out with the purified GroEL protein or BSA (non-adhesive protein control), cells were preincubated for $15 \mathrm{~min}$ at $37^{\circ} \mathrm{C}$ under a $5 \% \mathrm{CO}_{2}$ atmosphere with 10,50 and $75 \mu$ g protein $\mathrm{ml}^{-1}$ in Modified Eagle’s Medium 
(Life Technologies) before bacteria were put into contact with cells for $1 \mathrm{~h}$. Non-adherent bacteria were eliminated by five washings in PBS $(10 \mathrm{mM}$ phosphate buffer, $150 \mathrm{mM} \mathrm{NaCl}$, $\mathrm{pH} 7 \cdot 0$ ) and the cells were fixed and stained with MayGrünwald-Giemsa (Sigma). The adhesion index is given as the mean number of adhering bacteria per cell \pm SD (counted at a magnification of $1000 \times$ ) from at least three different assays. The significance of differences between various treatments was assessed by a Student's $t$-test.

Expression of GroEL induced by contact with target cells. Exponential-phase C. difficile 79-685 (anaerobic culture in $100 \mathrm{ml} \mathrm{TGY}$ at $37^{\circ} \mathrm{C}$ for $6 \mathrm{~h}$ ) were collected by centrifugation and washed twice in $\mathrm{PBS}, \mathrm{pH} 6 \cdot 8$, prior to application to the Vero cell monolayer. After $1 \mathrm{~h}$ adherence under anaerobic conditions, bacteria and cells were scraped off the tissue culture flasks with a rubber policeman and collected by centrifugation $(10 \mathrm{~min}, 5000 \mathrm{~g})$. After washing twice in PBS, the pellet was resuspended in $1.5 \mathrm{ml} 0 \cdot 1 \mathrm{M}$ Tris/ $\mathrm{HCl}, \mathrm{pH} 8 \cdot 6$, and proteins were extracted by three successive freeze-thaw cycles. After centrifugation at $15000 \mathrm{~g}$ for $15 \mathrm{~min}$, the supernatant was recovered and proteins present in it were separated by SDS-PAGE. GroEL was detected by immunoblotting as described above. The induction of expression of GroEL by contact with eukaryotic cells was evaluated by densitometric scanning of the bands. The C. difficile gelatinase (Poilane et al., 1998), a non-adhesive protein, served as a negative control.

DNA manipulations. Plasmid isolations were performed by the alkaline lysis procedure using a kit from Qiagen. Ligations and restriction endonuclease digestions were done according to Sambrook et al. (1989) and protocols provided by vendors. The TSB method was used for transformation of E. coli (Chung et al., 1989).

Computer analyses. Nucleotide and amino acid sequence alignments were performed with the CLUSTALX program (Thompson et al., 1997). Homology searches were conducted with FASTA3 (European Bioinformatics Institute) or BLAST (National Institute for Biotechnology Information, Washington, DC). Hairpin loops in DNA were searched for using RNAdraw (Matzura \& Wennborg, 1996).

\section{RESULTS AND DISCUSSION}

HSPs are considered to be major antigens in a number of bacterial pathogens and several micro-organisms express immunogenic GroEL homologues, giving rise to an immunogenic host response (Zugel \& Kaufmann, 1999). Infection with bacterial pathogens is accompanied by upregulation of expression of bacterial HSPs in response to various stress stimuli. However, limited information concerning direct interaction between HSPs and the host or about the function of stress proteins in disease pathogenicity is available. An example of an Hsp60 with a defined biological function is the $66 \mathrm{kDa}$ Hsp60 homologue of Salmonella typhimurium, which has been shown to be responsible for binding to intestinal mucus (Ensgraber \& Loos, 1992). Haemophilus ducryei produces a GroEL HSP which is associated with the cell surface and has the capacity to bind eukaryotic cells (Frisk et al., 1998). Several years ago we demonstrated that $C$. difficile adherence to various tissue culture cells, including intestinal Caco-2 and mucus-secreting HT-29MTX cells, is increased by a heat shock (Eveillard et al., 1993). We supposed that C. difficile finds itself in very stressful surroundings after destruction of the normal flora by antibiotic treatment. Indeed, in a later study we presented evidence that $C$. difficile adherence to tissue culture cells is augmented in a microenvironment deviating from that found in the large intestine under equilibrium, i.e. high osmolarity, low $\mathrm{pH}$ and iron insufficiency (Waligora et al., 1999). Under these conditions, C. difficile expresses three surface proteins that bind to radiolabelled cell membranes, one of which could be the GroEL protein (Waligora et al., 1999).

\section{Analysis of the groESL operon from C. difficile}

The $1940 \mathrm{bp}$ groELS operon of C. difficile 79-685, isolated by PCR, is composed of the 285 bp groES gene which has the capacity of encoding a 10198 Da protein $(\mathrm{pI}=4.93)$ and the $1623 \mathrm{bp}$ groEL gene with the capacity of encoding a 57677 Da protein $(\mathrm{pI}=4.72)$ (Fig. 1). The genes are separated by a $32 \mathrm{bp}$ non-coding sequence. The $\mathrm{G}+\mathrm{C}$ content of groES is $34 \mathrm{~mol} \%$ and that of groEL is $33 \mathrm{~mol} \%$. Analysis of the deduced protein sequence of GroEL revealed the presence of the peptide sequence AAVEEGIVAGGG at position 403-414 that is characteristic of the Hsp60 chaperone family [A-(AS)-X(DEQ)-E- $\left.\left(\mathrm{X}_{4}\right)-\mathrm{G}-\mathrm{G}-(\mathrm{GA})\right]$. Neither GroES nor GroEL possesses a signal peptide. Secondary structure prediction using the Chou \& Fasman (1978) algorithm revealed a predominantly $\alpha$-helical conformation with one potential transmembrane domain in the GroEL protein (Fig. 1). The 540 aa protein carries $28 \%$ charged residues. C. difficile GroEL displays best homology with that of C. acinetobutylicum ( $75 \%$ identity), C. thermocellum $(75 \%)$, C. perfringens $(74 \%)$ and Bacillus subtilis $(73 \%)$.

The nucleotide sequence upstream of groES carries two sequence motifs: (i) a 27 bp sequence resembling the CIRCE consensus sequence TTAGCACTC- ${ }_{9}$-GAGTGCTAA, an inverted repeat that could constitute the operator consensus binding site for HcrA, the negative regulator of class I heat-shock genes (Hecker et al., 1996; Mogk et al., 1997); (ii) sequences resembling $\sigma^{32}$ binding sites, the positive regulator of heat shock response genes (consensus sequence AAATC- $\mathrm{N}_{15^{-}}$ TAXTGYTTZTA where $\mathrm{X}=\mathrm{A} / \mathrm{T} ; \mathrm{Y}=\mathrm{C} / \mathrm{T} ; \mathrm{Z}=$ $\mathrm{T} / \mathrm{G}$ ) (Haldenwang, 1995) (Fig. 1). Some groELS operons are both positively and negatively regulated, as appears to be the case for C. difficile, whilst others have either CIRCE or the $\sigma^{32}$ consensus binding site. The translation-termination codon is followed by an imperfect inverted repeat that can form a stem-loop structure with a $\Delta G\left(37^{\circ} \mathrm{C}\right)$ of $-114.7 \mathrm{~kJ}$; it could constitute a $\rho$-independent transcriptional terminator.

\section{groEL copy number}

In some bacteria groEL is found as multiple copies in the genome, so a genomic Southern blot was performed to determine if the C. difficile groEL gene is single or multi- 
CAAGATTATTTTCACCAATATTATAAAAAATTATTAAAAAAGGTATATTGAAAATTATGTGTGATTGGTATATTATAATAATTGTTAGCACTATATTAGA 100 $\begin{array}{ccc}-35 & -10 \\ \text { TAGAGTGATAATAAATAATAAGTATATATATAAATCTTCATATATAAGTAGTATTAATTCAAAATAACTAAAAACATAGGCGACCTAGTCTATTCTTAA } 200\end{array}$ $\begin{array}{llllllllllllllllllllllllllllll}\text { Rbs } & M & N & I & K & P & F & G & D & R & V & V & I & K & K & V & E & A & E & E & K & T & A & S & G & I & V & 26\end{array}$ TATTTTAGGAGGCGTGAATATATGAATATTAAACCATTTGGTGACAGGGTAGTAATTAAAAAAGTAGAAGCAGAAGAAAAAACTGCAAGTGGAATAGTTT 300

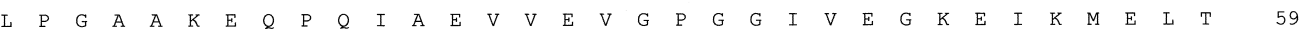
TACCAGGAGCAGCTAAAGAGCAACCTCAAATAGCTGAAGTTGTAGAAGTTGGACCAGGTGGAATAGTTGAAGGGAAAGAAATAAAAATGGAATTGACAGT 500

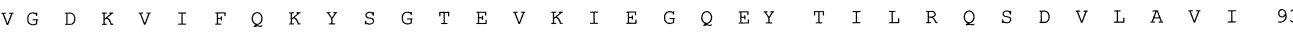
GGGAGATAAGGTTATATTCCAAAAATATTCTGGAACAGAAGTTAAGATAGAAGGACAAGAATACACAATACTAAGACAGAGTGATGTATTAGCTGTTATT 600

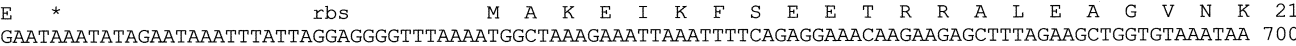

$\begin{array}{llllllllllllllllllllllllllllllllllll}\text { L } & A & D & T & V & K & V & T & L & G & P & K & G & R & N & V & I & L & D & K & K & F & G & S & P & L & I & T & N & D & G & V & T & 54\end{array}$ ATTAGCAGATACAGTAAAAGTAACATTAGGACCTAAAGGAAGAAATGTTATATTAGATAAAAAATTTGGTTCTCCACTTATAACTAATGATGGAGTAACT 800 $\begin{array}{lllllllllllllllllllllllllllllllllllllllllllllll}I & A & K & E & I & E & L & E & D & R & F & E & N & M & G & A & Q & L & V & K & E & V & A & T & K & T & N & D & V & A & G & D & G & 87\end{array}$ ATAGCAAAAGAGATAGAACTAGAAGATAGATTTGAAAATATGGGTGCTCAATTAGTTAAAGAAGTAGCAACTAAAACTAATGATGTAGCTGGAGATGGTA 900

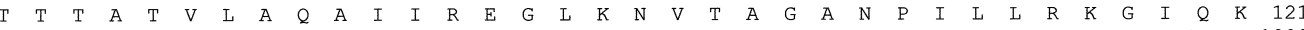
CTACAACTGCTACAGTTTTAGCACAAGCTATAATAAGAGAAGGTTTAAAGAATGTAACAGCAGGGGCTAACCCAATACTTTTAAGAAAAGGAATACAAAA 1000

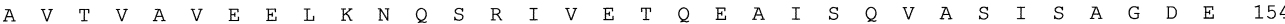
AGCAGTAACAGTAGCAGTAGAAGAATTAAAAAATCAATCAAGAATAGTAGAAACACAAGAGGCTATATCTCAAGTTGCTTCTATATCTGCTGGTGATGAA 1100

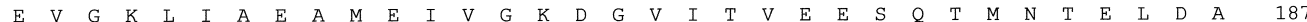
EAAG

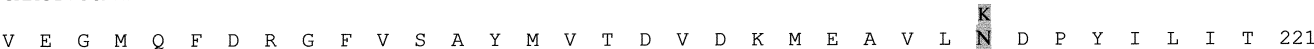
TTGAAGGTATGCAGTTTGATAGAGGATTTGTTTCTGCATATATGGTTACAGATGTAGATAAAATGGAAGCAGTTTTAAACGACCCATATATATTAATTAC 1300

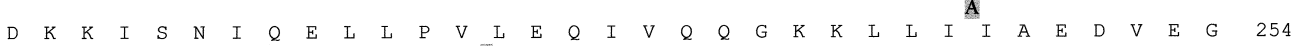
TGATAAAAAAATATCTAACATACAAGAATTATTACCAGTTCTTGAACAAATAGTTCAACAAGGTAAAAAGTTATTGATAATAGCTGAAGATGTAGAAGGT 1400

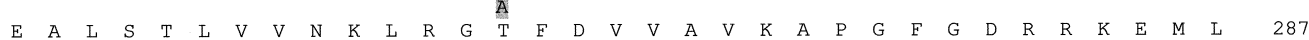
GAAGCATTATCTACATTAGTAGTAAATAAATTAAGAGGAACATTTGATGTAGTAGCAGTTAAAGCTCCAGGCTTTGGAGATAGAAGAAAAGAAATGCTTC 1500

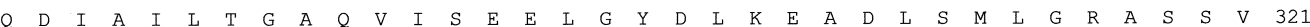
AAGATATAGCAATACTTACAGGTGCTCAAGTAATATCAGAAGAATTAGGTTATGATTTAAAAGAAGCTGATTTATCTATGCTAGGTAGAGCTTCATCTGT 1600

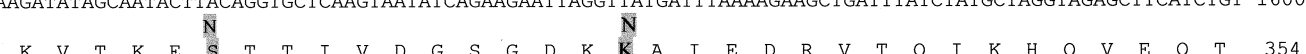

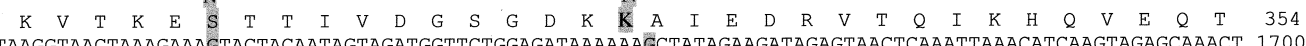
TAAGGTAACTAAAGAAAGTACTACAATAGTAGATGGTTCTGGAGATAAAAAAGCTATAGAAGATAGAGTAACTCAAATTAAACATCAAGTAGAGCAAACT 1700 $\begin{array}{lllllllllllllllllllllllllllllllllllllllllll}T & S & D & F & D & R & E & K & L & M & E & R & L & A & K & L & A & G & G & V & A & V & V & K & V & G & A & A & T & E & V & E & L & 387\end{array}$ ACTTCAGATTTTGATAGAGAGAAATTAATGGAAAGATTAGCTAAACTTGCTGGAGGAGTAGCTGTTGTAAAAGTTGGAGCTGCTACAGAAGTAGAGTTAA 1800

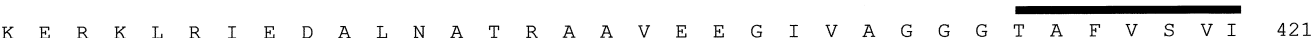
AAGAAAGAAAGTTAAGAATAGAAGATGCTCTTAATGCAACTAGAGCAGCTGTAGAAGAAGGAATAGTAGCTGGTGGAGGAACTGCTTTTGTTAGTGTTAT 1900

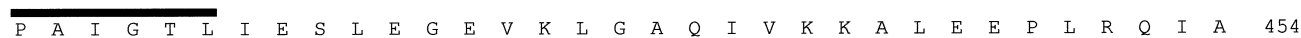
ACCAGCAATAGGAACACTAATTGAGAGTTTAGAAGGAGAAGTTAAACTAGGTGCTCAAATAGTTAAAAAAGCGTTAGAAGAGCCATTAAGACAAATAGCT 2000

$\begin{array}{lllllllllllllllllllllllllllllllllllll}I & N & A & G & L & E & G & A & V & I & V & Q & N & V & V & N & S & E & A & E & T & G & F & D & A & L & N & E & K & Y & V & N & M & 487\end{array}$ ATAAATGCTGGTCTTGAAGGTGCTGTAATTGTGCAAAATGTTGTTAATTCTGAAGCAGAAACTGGATTTGACGCATTGAATGAAAAATATGTAAATATGA 2100

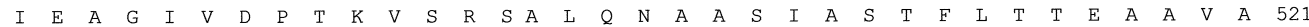
TAGAAGCTGGTATAGTTGACCCAACTAAAGTTAGTAGAAGTGCTTTACAAAATGCTGCATCAATAGCAAGTACTTTCTTAACTACTGAAGCTGCTGTTGC 2200

$\begin{array}{llllllllllllllllllllllllllll}D & \text { L } & P & E & K & E & D & A & G & M & P & G & T & G & M & D & G & M & Y & * & 540\end{array}$ TGACCTTCCTGAAAAAGAAGATGCAGGAATGCCAGGAACGGGCATGGACGGAATGTACTAATTTAAAAAATTTAAAATATAAATTTTAATATAAAGAACT 2300 ATTTCGACTTAGATTTTAAACTCTAAGTTGAAATAGTTCTTTTGTATATATCTAATTTTTGTATATCTATAAATTCAATACACATATTTAGATAATCAGT 2400

ATCTAGTTTGTAAT

Fig. 1. Nucleotide sequence and the deduced amino acid sequence of the groESL operon and upstream sequence of $C$. difficile strain 79-685 and ATCC 53603. The potential ribosome-binding sites (rbs) are underlined. An asterisk marks the stop codons. The nucleotide sequence resembling the CIRCE element in the promoter region is shaded in grey. The putative promoter region also carries consensus -35 and -10 binding sites for the $\sigma^{32}$ subunit of RNA polymerase (indicated in bold letters). A probable transcriptional terminator is indicated with inverted arrows. Divergent nucleotide and amino acid residues in GroEL of the strain ATCC 53603 are noted below and above the nucleotide sequence, respectively. A possible transmembrane domain is indicated with a solid bar (residues 415-427).

copy. A $340 \mathrm{bp}$ intragenic fragment was used to probe a Southern blot of genomic DNA isolated from 12 strains (Table 1) individually digested with two restriction enzymes. Employing low-stringency wash conditions, both enzymes produced only a single hybridizing band, suggesting that only a single genomic groEL locus is present (data not shown).

\section{PCR amplification and RFLP analysis of amplified groEL gene products}

As adhesins are attractive targets for the development of vaccines, we examined inter-strain variability of the groEL gene. Two internal oligonucleotide primers were used to amplify the groEL gene from 12 isolates (Table 
(a)

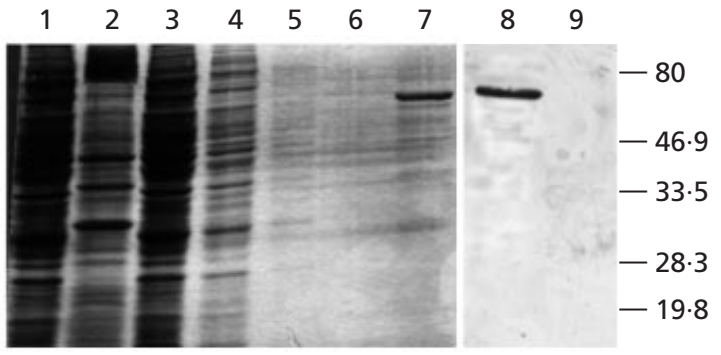

(b)
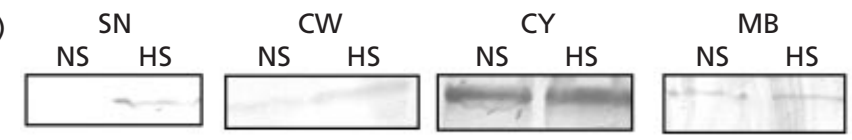

PepC
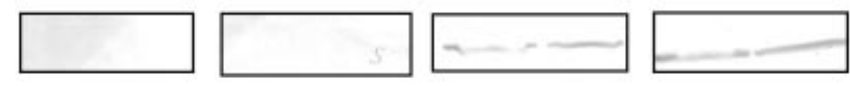

Cwp66-C
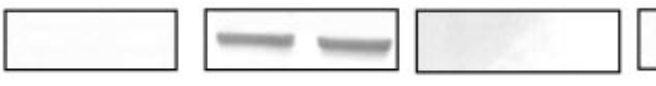

Fig. 2. (a) Purification of $C$. difficile GroEL overexpressed in $E$. coli BL21 and immunoblot analysis. Lanes: 1, total cell lysate from $4 \mathrm{I}$ culture analysed by SDS-PAGE; 2, soluble protein fraction (supernatant of lysed bacteria); 3 , insoluble protein fraction (bacterial pellet); 4-6, successive washes of soluble protein fraction incubated with glutathione-Sepharose beads; 7, final eluate after cleavage with Prescission protease showing a $58 \mathrm{kDa}$ protein corresponding to $C$. difficile GroEL. After SDS-PAGE, the purified protein was transferred to a membrane and incubated with polyclonal serum raised against C. difficile GroEL (dilution 1:2000) (lane 8) or preimmune rabbit serum at the same dilution (lane 9). Molecular mass markers (in $\mathrm{kDa}$ ) are indicated on the right (low-range molecular mass marker from Bio-Rad). (b) Localization of GroEL by fractionation experiments. Clostridial proteins were fractionated into four compartments: supernatant (SN), cell wall (CW), cytoplasm (CY) and membrane (MB). Equivalent amounts of each fraction were separated by PAGE, transferred to nitrocellulose and submitted to immunodetection using GroEL antibody, PepC antibody (control for cytoplasmic and membrane fractions) and Cwp66-C antibody (cell wall protein in C. difficile, thus serving as control for the CW fraction). NS, non-shocked; HS, heat shocked.

1). All strains yielded an amplified product of $1.45 \mathrm{~kb}$. The fragments were digested with AccI, AluI, DraI, EcoRV, HindIII, PvuII, ScaI and RsaI. All profiles obtained were identical except that of strain ATCC 53603 which with RsaI digestion exhibited a different pattern from the others (not shown). Sequencing of the gene from this strain showed an alteration of a nucleotide in an $R s a$ I site but the gene was more than $99 \%$ homologous to the one isolated from the strain 79-685 at the nucleotide and amino acid level (data not shown). Thus GroEL is highly conserved between strains and could be used as a candidate in vaccine preparations.

\section{Expression, purification, immunological detection and localization of GroEL}

We decided to purify the GroEL protein in order to obtain a polyclonal, monospecific antiserum for GroEL permitting functional studies. groEL was expressed as a fusion with GST in E. coli and purified by affinity chromatography. As shown in Fig. 2(a), lane 7, a $58 \mathrm{kDa}$ band corresponding to GroEL was observed in the eluate by SDS-PAGE. N-terminal sequencing of 21 aa of the purified protein revealed the sequence GPLGSPEFEGFKMAKEIKFSE, which is identical to the Nterminal amino acid sequence deduced from the groEL nucleotide sequence (residues in bold are the remaining GST residues encoded by pGEX-6P-1).

The $58 \mathrm{kDa}$ band was cut out of the gel and injected into rabbits to obtain polyclonal antibodies. The monospecific antiserum thus obtained reacted with the purified $58 \mathrm{kDa}$ GroEL protein (Fig. 2a, lane 8) in Western blots. Furthermore, a monoclonal antiserum raised against $M$. tuberculosis Hsp60 recognized C. difficile GroEL in Western blots (not shown).

Earlier studies had indicated that Hsp60 and Hsp70 (DnaK) are in general cytoplasmic proteins, but more recent studies suggest that they are membrane associated in some micro-organisms or secreted from the cells. If a protein is to serve as an adhesin, surface localization is required. GroEL of numerous bacteria, such as Legionella pneumophila (Garduno et al., 1998a, b; Hoffman et al., 1990), Helicobacter pylori (Cao et al., 1998; Dunn et al., 1997; Eschweiler et al., 1993; Huesca et al., 1996, 1998; Kamiya et al., 1998; Phadnis et al., 1996; Vanet \& Labigne, 1998; Yamaguchi et al., 1996a, b, 1997, 1998), Haemophilus ducreyi (Frisk et al., 1998; Parsons et al., 1997), M. avium (Rao et al., 1994), S. typhimurium (Ensgraber \& Loos, 1992), Actinobacillus actinomycetemcomitans (Goulhen et al., 1998) and Borrelia burgdorferi (Kaneda et al., 1997), has been shown to be involved in adhesion or invasion of various target cells or tissues and can be surface localized. C. difficile grown at $37^{\circ} \mathrm{C}$ and heat shocked at $48^{\circ} \mathrm{C}$ was fractionated to determine the localization of GroEL. The proteins in each fraction were separated by SDSPAGE and analysed for GroEL by Western immunoblotting (Fig. 2b). The GroEL protein was found mostly in the cytoplasmic and membrane fractions as well as extracellularly. A small amount of protein was found in the cell wall fraction.

Localization of GroEL on whole bacteria was examined by immunoelectron microscopy and immunofluorescence. In the non-heat-shocked condition (Fig. 3a), little immunolabelling of bacteria was observed [mean 1.2 grains $(\mathrm{cm} \text { bacterial surface })^{-2}$ ]. More than twofold increase of grain density $\mathrm{cm}^{-2}$ was observed in bacteria shocked at $42{ }^{\circ} \mathrm{C}$ (mean 2.7 grains $\mathrm{cm}^{-2}$ ) (Fig. $3 \mathrm{~b})$ and a more than sixfold increase at $48^{\circ} \mathrm{C}(7 \cdot 7$ grains $\mathrm{cm}^{-2}$ ) (Fig. 3c) compared with non-heat-shocked bacteria. The ratio of density of bacterial associated grains compared to the background labelling increased at each temperature. After heat shock at $48^{\circ} \mathrm{C}$ the protein was associated with amorphous electron-dense, cell-surface associated material and was distributed in a relatively uniform fashion over the bacterial surface. After a heat shock, especially at $48{ }^{\circ} \mathrm{C}$, the GroEL protein was also found to be localized within the extracellular space. 

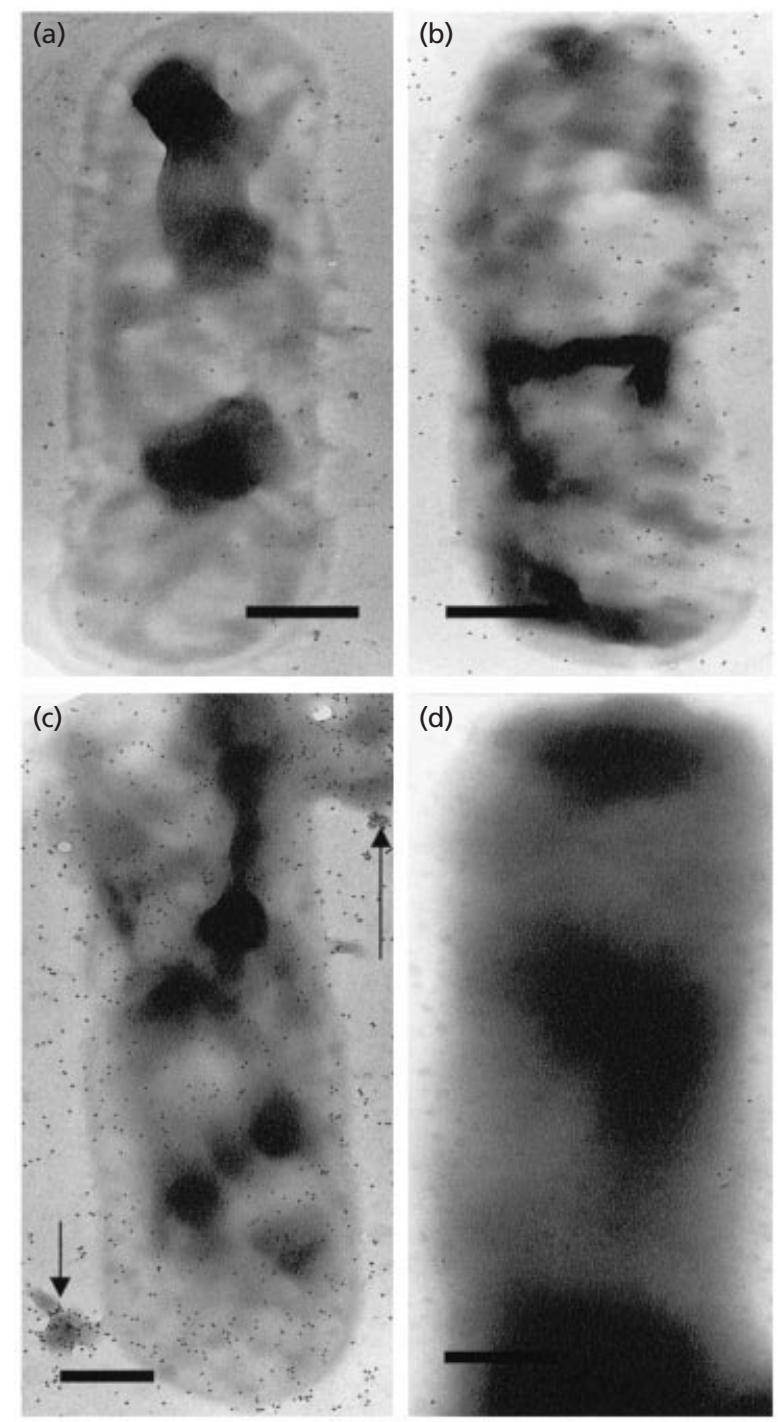

Fig. 3. Localization of $C$. difficile GroEL investigated by immunoelectron microscopy. (a) Representative electron micrograph of $C$. difficile 79-685 showing little labelling on whole bacterial cells which were grown at $37^{\circ} \mathrm{C}$ and not heat shocked. (b) A slight increase in labelling is observed after a heat shock at $42^{\circ} \mathrm{C}$. (c) Profuse labelling on the surface of an intact, whole bacterial cell heat shocked at $48^{\circ} \mathrm{C}$. The arrows indicate the filamentous material associated with the cell. Note the abundance of extracellular grains. (d) Whole bacterial cells incubated with the gold-labelled protein A-conjugated second antibody only served as a negative control. Bars, $0.3 \mu \mathrm{m}$.

Immunoblot analysis of proteins precipitated from the supernatant of heat shocked but intact and viable bacteria confirmed the presence of Hsp60 in this localization (data not shown).

The results obtained by immunoelectron microscopy were further corroborated by indirect immunofluorescent investigations of whole bacteria, using antibodies directed against GroEL, whole C. difficile or PepC, an intracellular protein. As shown in Fig. 4, heat shocked whole C. difficile bacteria showed strong
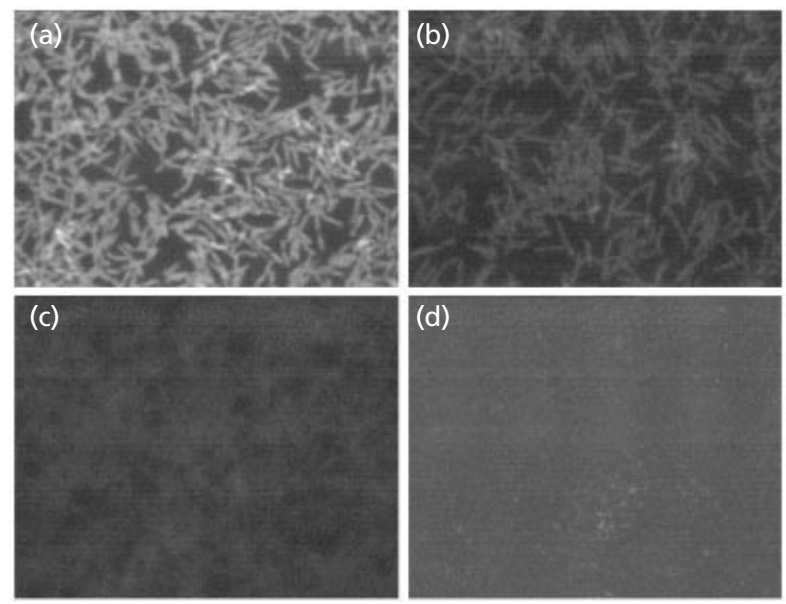

Fig. 4. Localization of $C$. difficile GroEL by indirect immunofluorescence. Photomicrographs of heat shocked $C$. difficile 79-685 visualized by immunofluorescence, with GroEL antiserum (a) or C. difficile antiserum (b) as the primary antibody and TRITC (tetramethylrhodamine isothiocyanate)labelled anti-mouse immunoglobulin as the secondary antibody. No fluorescent staining was observed when PepC antiserum (c) was used or when the primary antibody was omitted (d).

fluorescence with the first two antisera, whereas antibodies against the intracellular PepC did not react with these cells. These results confirm the surface association of GroEL on heat shocked bacteria.

How Hsp60 of C. difficile ends up on the bacterial surface is unclear at the moment as the protein carries no classical signal peptide. Several hypotheses can be proposed: (i) the protein is released by autolysis in the extracellular space and then adsorbed to adjacent bacteria as described for H. ducreyi and H. pylori (Frisk et al., 1998; Phadnis et al., 1996), although this finding concerning $H$. pylori has been contested (Vanet \& Labigne, 1998). We did not observe any lysis of bacteria after heat shock and bacteria remained viable (data not shown); thus this hypothesis does not appear to be valid for C. difficile; (ii) the protein is secreted involving type III secretion machinery or a simpler system such as an $\mathrm{ABC}$ transporter; however, so far this has not been shown in C. difficile; (iii) the protein is artefactually associated with the membrane because of its chaperone function after release (Bukau et al., 1993). The hydrophobic domains, located in the C-terminal portion of GroEL, could facilitate its interaction with hydrophobic regions of other proteins as well as with hydrophobic regions of molecules such as phospholipids or lipopolysaccharides. The results presented here seem to favour extracellular release followed by surface adsorption. This hypothesis is supported by the fact that GroEL was detected extracellularly after precipitation of proteins from culture supernatant, even when heat shocked bacteria remained intact and viable (data not shown). 


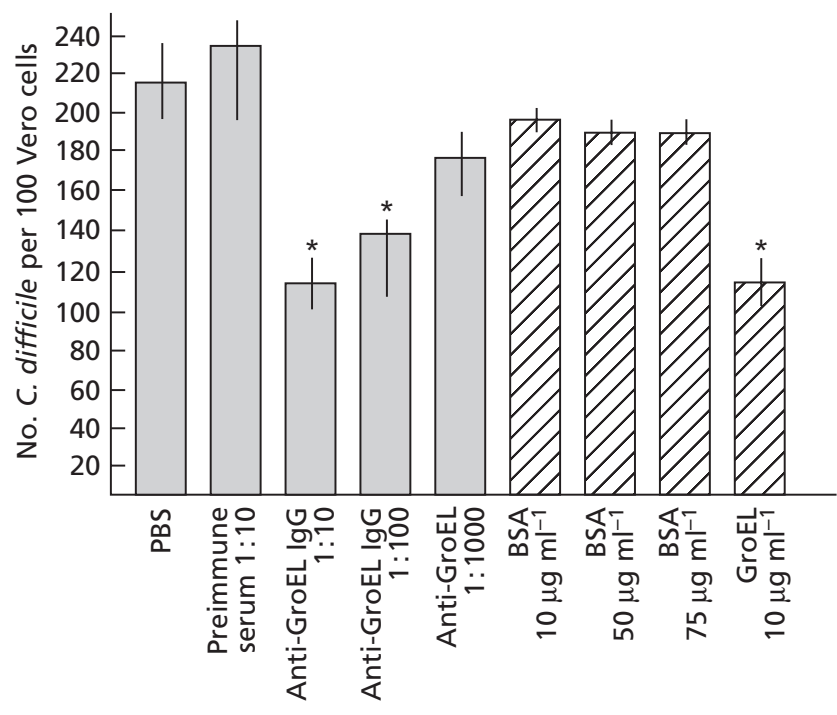

Fig. 5. Inhibition of $C$. difficile adherence to tissue culture cells by antibodies and purified GroEL. Adherence was determined in the presence of PBS, preimmune serum (negative controls) and various concentrations of GroEL antibodies, purified GroEL $\left(10 \mu \mathrm{g} \mathrm{ml}^{-1}\right.$ shown; at higher concentrations cells were damaged and counting of adherent bacteria was therefore not accurate) or BSA (negative control; a non-adhesive protein). Values shown are the mean \pm SD of at least four separate experiments. *, Statistically significant difference (Student's $t$ test; $P<0.05)$ compared to controls.

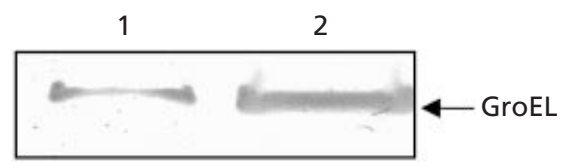

Fig. 6. Increase in GroEL expression after contact with target cells. GroEL was detected by immunoblotting (1:2000 dilution of antibodies). Lane 1, proteins isolated from bacteria that had not been attached to eukaryotic cells, separated by SDS-PAGE and blotted onto a membrane. Lane 2, proteins isolated from bacteria after $1 \mathrm{~h}$ contact with eukaryotic cells. Each lane contains proteins from equivalent numbers of bacteria. Densitometric scanning of bands revealed a $2 \cdot 5$-fold induction in the presence of eukaryotic cells.

\section{GroEL plays a role in cell adherence}

The fact that C. difficile cell attachment is increased by stress and the presence of GroEL on the bacterial cell surface suggests a possible role for this protein in cell adherence. Involvement of the Hsp60 in adhesion of $C$. difficile to eukaryotic cells was investigated in competitive inhibition assays using anti-GroEL antibodies or the purified protein. As shown in Fig. 5, co-incubation of bacteria with antibodies at a dilution of $1: 10$ demonstrated a relative adherence of $55 \%$ compared with the control (incubation with preimmune serum at the same dilution), indicating that Hsp60 may indeed be involved in the adherence process. A significant reduction of adherence was also observed at 1:100 dilution of antibodies, whereas at 1:1000 dilution the decrease was not significant. Furthermore, the purified protein inhibited cell adherence by $50 \%$ at a concentration of $10 \mu \mathrm{g} \mathrm{m} l^{-1}$. In contrast, no inhibition was observed when competitive inhibition was carried out with the non-adhesive protein BSA. As in H. ducreyi (Frisk et al., 1998), the partial inhibition can be explained by the likelihood of having multiple adhesins and mechanisms involved in adherence of $\mathrm{C}$. difficile. We are in the process of characterizing some of the other adhesins.

Indirect evidence for the role of GroEL in cell adherence is presented in Fig. 6. The expression of GroEL was induced when the bacteria were in contact with target cells under conditions that do not involve thermal stress. Densitometric scanning of the bands revealed a $2 \cdot 5$-fold increase in expression of GroEL following cell contact. Expression of the non-adhesive protein gelatinase, used as a negative control, was not induced (data not shown). We speculate that cell contact could send a signal to $C$. difficile, the result of which is increased expression of the GroEL protein and its subsequent surface display. Others (Qoronfleh et al., 1998) have shown a de novo synthesis of proteins involved in cell adherence or invasion upon epithelial cell contact.

In conclusion, we provide evidence in this communication that GroEL of $C$. difficile serves an adhesive function in this bacterium. As in other bacteria, $C$. difficile is likely to possess multiple adhesins and we are pursuing studies to elucidate the role of each. Furthermore, investigations are underway in our laboratory to evaluate the capacity of GroEL to trigger a protective immune response.

\section{ACKNOWLEDGEMENTS}

This work was supported in part by the FAIR Programme of the European Union CT95-0433. We thank Professor M. Delmée (Université Catholique de Louvain, Belgium) for kindly providing the ATCC strains listed in Table 1 and Dr P. Mullany (Eastman Dental Institute, London, UK) for providing strain 630. The aid of Ms D. Jaillard (Service de Microscopie Electronique, University of Paris-Sud Orsay) in electron microscopy was greatly appreciated. The PepC antibody was a kind gift from Dr M.-Y. Mistou, INRA, Jouyen-Josas, France.

\section{REFERENCES}

Bartlett, J. G., Chang, T. W., Gurwith, M., Gorbach, S. L. \& Onderdonk, A. B. (1978). Antibiotic-associated pseudomembranous colitis due to toxin-producing clostridia. N Engl J Med 298, 531-534.

Borriello, S. P., Welch, A. R., Barclay, F. E. \& Davies, H. A. (1988a). Mucosal association by Clostridium difficile in the hamster gastrointestinal tract. J Med Microbiol 25, 191-196.

Borriello, S. P., Davies, H. A. \& Barclay, F. E. (1988b). Detection of fimbriae amongst strains of Clostridium difficile. FEMS Microbiol Lett 49, 65-67.

Bukau, B., Reilly, P., McCarty, J. \& Walker, G. C. (1993). Immunogold localization of the DnaK heat shock protein in Escherichia coli cells. J Gen Microbiol 139, 95-99. 
Cao, P., McClain, M. S., Forsyth, M. H. \& Cover, T. L. (1998). Extracellular release of antigenic proteins by Helicobacter pylori. Infect Immun 66, 2984-2986.

Chou, P. Y. \& Fasman, G. D. (1978). Prediction of the secondary structure of proteins from their amino acid sequence. $A d v$ Enzymol Relat Areas Mol Biol 47, 45-48.

Chung, C. T., Niemela, S. L. \& Miller, R. H. (1989). One-step preparation of competent Escherichia coli: transformation and storage of bacterial cells in the same solution. Proc Natl Acad Sci US A 86, 2172-2175.

Davies, H. A. \& Borriello, S. P. (1990). Detection of capsule in strains of Clostridium difficile of varying virulence and toxigenicity. Microb Pathog 9, 141-146.

Dunn, B. E., Vakil, N. B., Schneider, B. G., Miller, M. M., Zitzer, J. B., Peutz, T. \& Phadnis, S. H. (1997). Localization of Helicobacter pylori urease and heat shock protein in human gastric biopsies. Infect Immun 65, 1181-1188.

Ensgraber, M. \& Loos, M. (1992). A 66-kilodalton heat shock protein of Salmonella typhimurium is responsible for binding of the bacterium to intestinal mucus. Infect Immun 60, 3072-3078.

Eschweiler, B., Bohrmann, B., Gerstenecker, B., Schiltz, E. \& Kist, M. (1993). In situ localization of the $60 \mathrm{k}$ protein of Helicobacter pylori, which belongs to the family of heat shock proteins, by immunoelectron microscopy. Zentbl Bakteriol 280, 73-85.

Eveillard, M., Fourel, V., Barc, M. C., Kerneis, S., Coconnier, M. H., Karjalainen, T., Bourlioux, P. \& Servin, A. L. (1993). Identification and characterization of adhesive factors of Clostridium difficile involved in adhesion to human colonic enterocyte-like Caco-2 and mucus-secreting HT29 cells in culture. Mol Microbiol 7, 371-381.

Frisk, A., Ison, C. A. \& Lagergard, T. (1998). GroEL heat shock protein of Haemophilus ducreyi : association with cell surface and capacity to bind to eukaryotic cells. Infect Immun 66, 1252-1257.

Garduno, R. A., Faulkner, G., Trevors, M. A., Vats, N. \& Hoffman, P. S. (1998a). Immunolocalization of $\mathrm{Hsp} 60$ in Legionella pneumophila. J Bacteriol 180, 505-513.

Garduno, R. A., Garduno, E. \& Hoffman, P. S. (1998b). Surfaceassociated Hsp60 chaperonin of Legionella pneumophila mediates invasion in a HeLa cell model. Infect Immun 66, 4602-4610.

George, W. L. (1984). Antimicrobial agent-associated colitis and diarrhoea: historical background and clinical aspects. Rev Infect Dis 6 (Suppl 1), S208-S213.

Goulhen, F., Hafezi, A., Uitto, V. J., Hinode, D., Nakamura, R., Grenier, D. \& Mayrand, D. (1998). Subcellular localization and cytotoxic activity of the GroEL-like protein isolated from Actinobacillus actinomycetemcomitans. Infect Immun $\mathbf{6 6}$, 5307-5313.

Haldenwang, W. G. (1995). The sigma factors of Bacillus subtilis. Microbiol Rev 59, 1-30.

Hecker, M., Schumann, W. \& Volker, U. (1996). Heat-shock and general stress response in Bacillus subtilis. Mol Microbiol 19, 417-428.

Hoffman, P. S., Houston, L. \& Butler, C. A. (1990). Legionella pneumophila htpAB heat shock operon: nucleotide sequence and expression of the 60-kilodalton antigen in L. pneumophilainfected HeLa cells. Infect Immun 58, 3380-3387.

Huesca, M., Borgia, S., Hoffman, P. \& Lingwood, C. A. (1996). Acidic $\mathrm{pH}$ changes receptor binding specificity of Helicobacter pylori: a binary adhesion model in which surface heat shock (stress) proteins mediate sulfatide recognition in gastric colonization. Infect Immun 64, 2643-2648.

Huesca, M., Goodwin, A., Bhagwansingh, A., Hoffman, P. \& Lingwood, C. A. (1998). Characterization of an acidic-pH-inducible stress protein (hsp70), a putative sulfatide binding adhesin, from Helicobacter pylori. Infect Immun 66, 4061-4067.

Jonquières, R., Bierne, H., Fiedler, F., Gounon, P. \& Cossart, P. (1999). Interaction between the protein InlB of Listeria monocytogenes and lipoteichoic acid: a novel mechanism of protein association at the surface of gram-positive bacteria. Mol Microbiol 34, 902-914.

Kamiya, S., Yamaguchi, H., Osaki, T. \& Taguchi, H. (1998). A virulence factor of Helicobacter pylori: role of heat shock protein in mucosal inflammation after $H$. pylori infection. J Clin Gastroenterol 27, S35-S39.

Kaneda, K., Masuzawa, T., Yasugami, K., Suzuki, T., Suzuki, Y. \& Yanagihara, Y. (1997). Glycosphingolipid-binding protein of Borrelia burgdorferi sensu lato. Infect Immun 65, 3180-3185.

Karjalainen, T., Barc, M. C., Collignon, A., Trolle, S., Boureau, H., Cotte-Laffitte, J. \& Bourlioux, P. (1994). Cloning of a genetic determinant from Clostridium difficile involved in adherence to tissue culture cells and mucus. Infect Immun 62, 4347-4355.

Laemmli, U. K. (1970). Cleavage of structural proteins during the assembly of the head of bacteriophage T4. Nature 227, 680-685. Lyerly, D. M., Krivan, H. C. \& Wilkins, T. D. (1988). Clostridium difficile: its disease and toxins. Clin Microbiol Rev 1, 1-18.

Matzura, O. \& Wennborg, A. (1996). RNAdraw: an integrated program for RNA secondary structure calculation and analysis under 32-bit Microsoft Windows. Comput Appl Biosci 12, 247-249.

Mogk, A., Homuth, G., Scholz, C., Kim, L., Schmid, F. X. \& Schumann, W. (1997). The GroE chaperonin machine is a major modulator of the CIRCE heat shock regulon of Bacillus subtilis. EMBO J 16, 4579-4590.

Parsons, L. M., Limberger, R. J. \& Shayegani, M. (1997). Alterations in levels of DnaK and GroEL result in diminished survival and adherence of stressed Haemophilus ducreyi. Infect Immun 65, 2413-2419.

Phadnis, S. H., Parlow, M. H., Levy, M., Ilver, D., Caulkins, C. M., Connors, J. B. \& Dunn, B. E. (1996). Surface localization of Helicobacter pylori urease and a heat shock protein homolog requires bacterial autolysis. Infect Immun 64, 905-912.

Poilane, I., Karjalainen, T., Barc, M. C., Bourlioux, P. \& Collignon, A. (1998). Protease activity of Clostridium difficile strains. Can J Microbiol 44, 157-161.

Qoronfleh, M. W., Bortner, C. A., Schwartzenberg, P. \& Wilkinson, B. J. (1998). Enhanced levels of Staphylococcus aureus stress protein GroEL and DnaK homologs early in infection of human epithelial cells. Infect Immun 66, 3024-3027.

Rao, S. P., Ogata, K., Morris, S. L. \& Catanzaro, A. (1994). Identification of a $68 \mathrm{kD}$ surface antigen of Mycobacterium avium that binds to human macrophages. J Lab Clin Med 123, 526-535.

Rusanganwa, E., Singh, B. \& Gupta, R. S. (1992). Cloning of HSP60 (GroEL) operon from Clostridium perfringens using a polymerase chain reaction based approach. Biochim Biophys Acta 1130, 90-94.

Sambrook, J., Fritsch, E. F. \& Maniatis, T. (1989). Molecular Cloning: a Laboratory Manual, 2nd edn. Cold Spring Harbor, NY: Cold Spring Harbor Laboratory.

Schubert, K., Bichlmaier, A. M., Mager, E., Wolff, K., Ruhland, G. 
\& Fiedler, F. (2000). P45, an extracellular $45 \mathrm{kDa}$ protein of Listeria monocytogenes with similarity to protein $\mathrm{p} 60$ and exhibiting peptidoglycan lytic activity. Arch Microbiol 173, 21-28.

Seddon, S. V. \& Borriello, S. P. (1992). Proteolytic activity of Clostridium difficile. J Med Microbiol 36, 307-311.

Tasteyre, A., Barc, M.-C., Karjalainen, T., Dodson, P., Hyde, S., Bourlioux, P. \& Borriello, P. (2000). A Clostridium difficile gene encoding flagellin. Microbiology 146, 957-966.

Thompson, J. D., Gibson, T. J., Plewniak, F., Jeanmougin, F. \& Higgins, D. G. (1997). The CLUSTAL_X windows interface: flexible strategies for multiple sequence alignment aided by quality analysis tools. Nucleic Acids Res 25, 4876-4882.

Vanet, A. \& Labigne, A. (1998). Evidence for specific secretion rather than autolysis in the release of some Helicobacter pylori proteins. Infect Immun 66, 1023-1027.

Waligora, A. J., Barc, M.-C., Bourlioux, P., Collignon, A. \& Karjalainen, T. (1999). Clostridium difficile cell attachment is modified by environmental factors. Appl Environ Microbiol 65, 4234-4238.

Yamaguchi, H., Osaki, T., Taguchi, H., Hanawa, T., Yamamoto, T. \& Kamiya, S. (1996a). Induction and epitope analysis of Helico- bacter pylori heat shock protein. J Gastroenterol 31 (Suppl 9), $12-15$.

Yamaguchi, H., Osaki, T., Taguchi, H., Hanawa, T., Yamamoto, T. \& Kamiya, S. (1996b). Flow cytometric analysis of the heat shock protein 60 expressed on the cell surface of Helicobacter pylori. J Med Microbiol 45, 270-277.

Yamaguchi, H., Osaki, T., Kurihara, N., Taguchi, H., Hanawa, T., Yamamoto, T. \& Kamiya, S. (1997). Heat-shock protein 60 homologue of Helicobacter pylori is associated with adhesion of H. pylori to human gastric epithelial cells. J Med Microbiol 46, 825-831.

Yamaguchi, H., Osaki, T., Taguchi, H., Hanawa, T., Yamamoto, T. \& Kamiya, S. (1998). Relationship between expression of HSP60, urease activity, production of vacuolating toxin, and adherence activity of Helicobacter pylori. J Gastroenterol 33, 6-9.

Zugel, U. \& Kaufmann, S. H. (1999). Role of heat shock proteins in protection from and pathogenesis of infectious diseases. Clin Microbiol Rev 12, 19-39.

Received 1 June 2000; revised 15 September 2000; accepted 26 September 2000. 